\title{
Resistivity and AE Response Characteristics in the Failure Process of CGB under Uniaxial Loading
}

\author{
Tingye Qi ${ }^{1,2}$ and Guorui Feng ${ }^{2,3}$ \\ ${ }^{1}$ Institute of Mining Technology, Taiyuan University of Technology, Taiyuan, Shanxi 030024, China \\ ${ }^{2}$ Shanxi Province Research Center of Green Mining Engineering Technology, Taiyuan 030024, China \\ ${ }^{3}$ College of Mining Technology, Taiyuan University of Technology, Taiyuan 030024, China \\ Correspondence should be addressed to Guorui Feng; fguorui@163.com
}

Received 20 December 2016; Accepted 29 March 2017; Published 10 April 2017

Academic Editor: Wei Zhou

Copyright (C) 2017 Tingye Qi and Guorui Feng. This is an open access article distributed under the Creative Commons Attribution License, which permits unrestricted use, distribution, and reproduction in any medium, provided the original work is properly cited.

\begin{abstract}
To understand the characteristics of the acoustic emission (AE) and electrical resistivity of cemented coal gangue backfill (CGB) under uniaxial compression, the variations in these characteristics at 1 day, 3 days, and 7 days are analyzed by means of a stressstrain-resistivity-AE test, and the microperformances are investigated. The research results indicate that the AE can reflect the initiation and propagation of cracks and later explain the variation of the resistivity of the specimens under the uniaxial loading. The cumulative energy curve of $\mathrm{AE}$ is approximately two straight lines corresponding to the peak stress, and the difference in the linear slope gradually decreased with the increasing curing time due to the lower pore solution content and the compact pore structure. The relationships between the stress and resistivity and the loading condition before and after the peak stress at different curing times were established. Therefore, it is of great significance to predict the stability of the filling body by monitoring the AE and resistivity variations of the filling body. In addition, it is possible to calculate the roof stress using the relation equation between the resistivity and stress.
\end{abstract}

\section{Introduction}

The cemented coal gangue backfill (CGB) is mixed with the cement, gangue, fly ash, and other solid wastes transported through the pipeline to the goaf and forms the filling body after solidification as "artificial rock" to effectively control the surface subsidence and reduce the pollution of the environment $[1,2]$. The stability monitoring of the filling body is of great significance to the evaluation of the filling effect and the optimization of the filling materials $[3,4]$. Under the action of the vertical stress of the roof, changes will occur to the internal structure of the filling body, such as the compaction of the pore structure and the generation and growth of cracks, reflecting changes in the macrophysical fields, including changes in the displacement field and elastic wave release caused by AE phenomena and changes to the resistivity. The monitoring of the resistivity and $\mathrm{AE}$ characteristics can reflect the stability of the filling body [5-7].
Many scholars have studied the variation and mechanism of the resistivity and $\mathrm{AE}$ characteristics of rock and concrete under uniaxial compression [8-10]. Saltas et al. $[11,12]$ made such experiments with electric earthquake precursors, summarizing results from laboratory results to field observations; they found that Ac-conductivity during linear loading is strongly correlated with the $\mathrm{AE}$ activity for limestone samples. Ji et al. [13] studied the frequency characteristics of the AE signals of granite under uniaxial compression and found that the $\mathrm{AE}$ count rate shows a periodic variation with the increasing relative stress. Guo et al. [14] monitored the whole compression test process of concrete specimens with different strength indices using $\mathrm{AE}$ and its location technology and analyzed the relationship between the characteristic parameters of the $\mathrm{AE}$ frequency in the loading failure process and the strength of the concrete. Hao et al. [15] applied uniaxial compression to rock samples and obtained the mechanism of the resistivity change during 
the rock failure process, considering that the existence of fissures and the saturated state of the solution are the two most important factors controlling the change of the resistivity before the main fracture. Chen and Lin [16] reported stressstrain-electric resistance experiments for diabase, limestone, and marble containing $\mathrm{NaCl}$ solution during the whole process of uniaxial compression and concluded that the change caused by the internal cracking of the rock causes the corresponding variation of the rock's electrical resistance. Chen et al. [17] tested the resistivity change characteristics of different coals under different loading modes and found that the variation characteristics of the resistivity are determined by both the conductivity characteristics of the coal and the evolution of the pore structure. $\mathrm{Li}$ et al. [18] tested the whole uniaxial compression process of sandstone using the joint test method of electrical resistivity and AE technology and concluded that the two sources of response information have strong regularity and complementarity. Wang et al. [19] studied the variation regularity of the stress and strain, $\mathrm{AE}$, and electrical resistivity of limestone and skarn rock under uniaxial loading conditions and established regression equations for the resistivity and elastic modulus in different damage stages. Moreover, some new methods as that of nonextensive statistical physics and natural time analysis were used for the analysis of $\mathrm{AE}$ in rocks under stress, which could be done on the scaling in pressure stimulated currents related with rock fracture $[20,21]$.

Based on the above analysis, we know that a large number of scholars performed deep and systematic research on the $\mathrm{AE}$ characteristics, internal failure forms, and resistivity variation of different lithologic rocks, coals, and concrete in the process of uniaxial loading. However, there have been few reports on the $\mathrm{AE}$ characteristics and the variation of the resistivity of CGB under uniaxial loading. As the early strength of the filling body has an important effect on the filling effect, based on the research of the above scholars, this paper analyzes the stress and strain, $\mathrm{AE}$, and resistivity response characteristics of CGB under uniaxial compression in the early curing period and reveals the failure form of the material by microscopic observations. The research of this paper is helpful to understand the damage evolution mechanism of CGB and grasp the precursory information and features of the $\mathrm{AE}$ and resistivity with respect to the strength and deformation of the CGB and serves as a theoretical basis for judging the stability and strength of the filling body.

\section{Sample Preparation and Test Methods}

2.1. Sample Preparation. Ordinary Portland cement and fly ash are used as the cementing material of the CGB in the test. The ordinary Portland cement (grade 42.5) was obtained from Taiyuan Lion Cement, Limited by Share Ltd., and the fly ash samples were obtained from the power plant of Xinyang Colliery. The mixing water is ordinary tap water, and the effects of ions in the water on the hydration process of the filling materials are not considered in the experiments. The coal gangue samples were obtained from Xinyang Colliery, and the waste is divided into fine gangue $(0-5 \mathrm{~mm})$, medium gangue $(5-10 \mathrm{~mm})$, and coarse gangue $(10-15 \mathrm{~mm})$ according to the particle size range. The mineral composition and chemical composition of the raw materials can be found in the literature [22].

Considering the requirements of the bleeding rate, slump, and strength of filling materials, the ratio of the raw materials was determined [23]: the fine gangue content accounted for $30 \%$ of the total amount of gangue with a dosage of $285 \mathrm{~kg} / \mathrm{m}^{3}$, and the medium and coarse gangue contents each accounted for $35 \%$ of the total amount of gangue, with dosages of $332.5 \mathrm{~kg} / \mathrm{m}^{3}$. The amounts of cement and fly ash were $190 \mathrm{~kg} / \mathrm{m}^{3}$ and $380 \mathrm{~kg} / \mathrm{m}^{3}$, respectively, and the mass concentration was $80 \%$.

After the raw materials were mixed and mechanically stirred, the slurry was transferred into $\Phi 50 \mathrm{~mm} * 100 \mathrm{~mm}$ testing molds. After removing the template after $24 \mathrm{~h}$, the specimens were placed in a curing room (temperature: $20 \pm$ $2^{\circ} \mathrm{C}$; humidity: $40 \%$ ). After periods of 1 day, 3 days, and 7 days, tests of the resistivity variation and $\mathrm{AE}$ characteristics were carried out under the uniaxial loading condition, in addition to a microscopic fracture observation test.

2.2. Testing Procedures and Equipment. The test press was a WAW-1000 KN microcomputer controlled electrohydraulic servo universal testing machine produced by the Ruifeng Co. in China, and the loading speed was controlled at a value of $0.002 \mathrm{~mm} / \mathrm{s}$. The resistivity testing was performed using a Zhongce resistivity tester, with a test method of dipole, a test voltage of $1 \mathrm{~V}$, a frequency of $100 \mathrm{~Hz}$, and a data acquisition frequency of 1 time per second. The AE testing system adopted the PCI-2 AE testing system produced by the Physical Acoustics Co. (PAC) in the United States, the preamplification was $40 \mathrm{~dB}$, the threshold value was $40 \mathrm{~dB}$, the probe resonance frequency was $20-100 \mathrm{kHz}$, and the sampling rate was 1 MSPS. Figure 1 shows the stress-strainresistivity-AE testing device. To ensure that the compressive test has a common time parameter with the AE test and the resistivity experiment makes the processing and analysis of data convenient between the loading system and AE system testing, the resistivity measurement system must ensure synchronization.

Vaseline was used to couple the contact surface of the AE probe and CGB specimen, and it was fixed with adhesive tape to ensure good signal reception [24]. An insulating film, a copper plate electrode, and a cotton cloth impregnated with copper sulfate solution were arranged in order between the loading platform and the test piece to reduce the influence of the contact resistance on the resistivity data. The test equipment is shown in Figure 2. The microstructure of the CGB sample after loading was observed by the German ZEISSEVO18 scanning electron microscope (SEM). After curing, the CGB particles were subjected to a porosity test using mercury intrusion porosimetry (MIP).

\section{Results and Discussion}

3.1. Change Features of Pore Structure. A differential distribution curve (Figure 2) is presented to estimate and evaluate the 


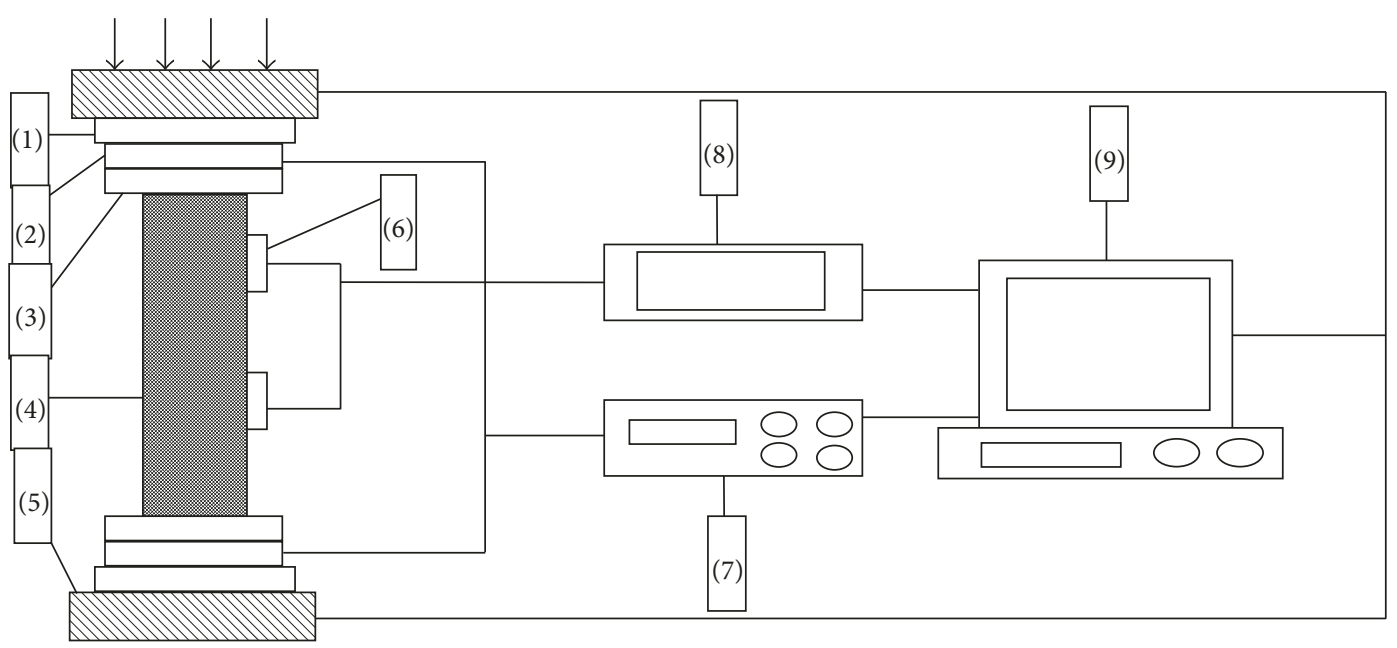
(1) Insulation pad
(2) Copper electrode
(3) Copper sulfate solution
(4) Sample
(5) Loading platform

(6) AE probe

(7) LCR tester

(8) AE instrument

(9) Stress control system; resistivity data acquisition system; stress-strain data acquisition system; AE data acquisition system

FIGURE 1: Stress-strain-resistivity testing device diagram.

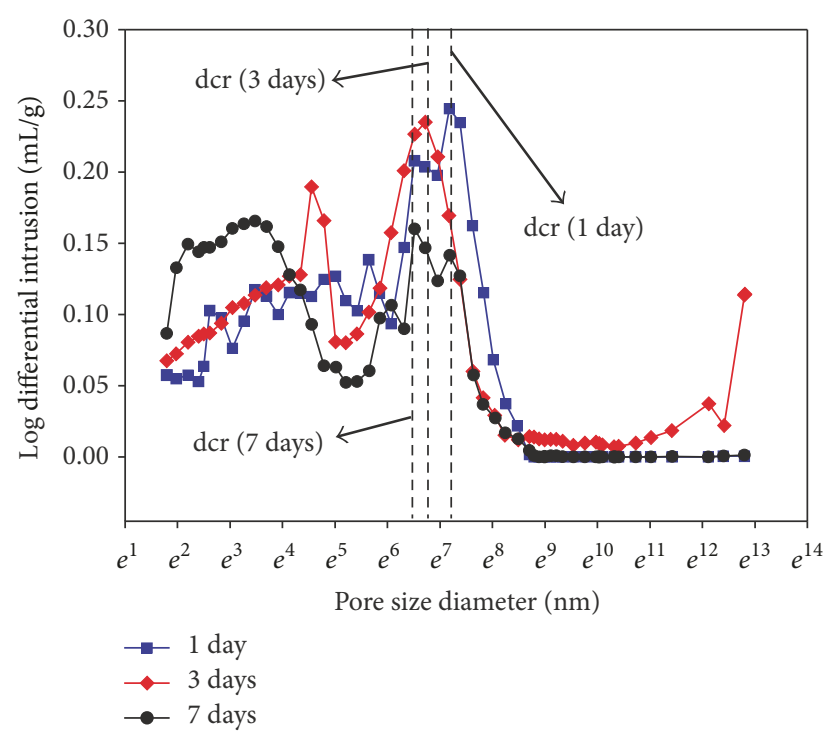

Figure 2: MIP pore size distribution at different curing times.

pore structure of the CGB at 1 day, 3 days, and 7 days. To estimate the critical pore size $\left(d_{\mathrm{cr}}\right)$, the differential distribution curve was plotted, where the critical pore size corresponds to the diameter at which the distribution presents as a maximum. The critical pore size controls the transmissivity of the material [25]. The critical pore diameter is the most frequently occurring diameter in the interconnected pores which allows the maximum percolation of chemical species through the CGB [26]. Figure 2 indicates that as the curing time increases, the critical diameter decreases. This leads
TABLE 1: Three types of pore diameter volume at natural curing condition.

\begin{tabular}{lccc}
\hline & \multicolumn{3}{c}{ Pore size distribution, $\mathrm{mL} / \mathrm{g}$} \\
Curing time & $\begin{array}{c}\text { Gel } \\
\text { micropores } \\
<10 \mathrm{~nm}\end{array}$ & $\begin{array}{c}\text { Middle } \\
\text { capillary } \\
\text { pores } 10 \mathrm{~nm} \sim \\
100 \mathrm{~nm}\end{array}$ & $\begin{array}{c}\text { Large } \\
\text { capillary } \\
\text { pores } \\
100 \mathrm{~nm} \sim \\
10 \mu \mathrm{m}\end{array}$ \\
\hline 1 day & 0.17032 & 1.163139 & 2.455594 \\
3 days & 0.220524 & 1.362947 & 2.196449 \\
7 days & 0.369275 & 1.727342 & 1.445802 \\
\hline
\end{tabular}

to the conclusion that the increasing curing time produces more reactive products and generates fewer interconnected pores in the CGB, although of the same magnitude. Moreover, with the increase in curing time, the decreased critical pore size makes the diffusion and permeability of the CGB lower to encourage the pore solution to flow through the pore structure, which weakens the current transport capacity of the pore solution.

According to Aligizaki et al. [27-29], the pore size range of the CGB can be divided into three sections, including gel micropores $(<10 \mathrm{~nm})$, middle capillary pores $(10-100 \mathrm{~nm})$, and large capillary pores $(100 \mathrm{~nm}-10 \mu \mathrm{m})$. On the basis of the MIP results, Table 1 presents the pore volumes of the different pore sizes with 1 day, 3 days, and 7 days. The gel micropore volume increased with the increasing curing time, while the large capillary pores decreased. The variation of the different pore size contents is closely related to the chemical reaction degree and evaporation of water inside 


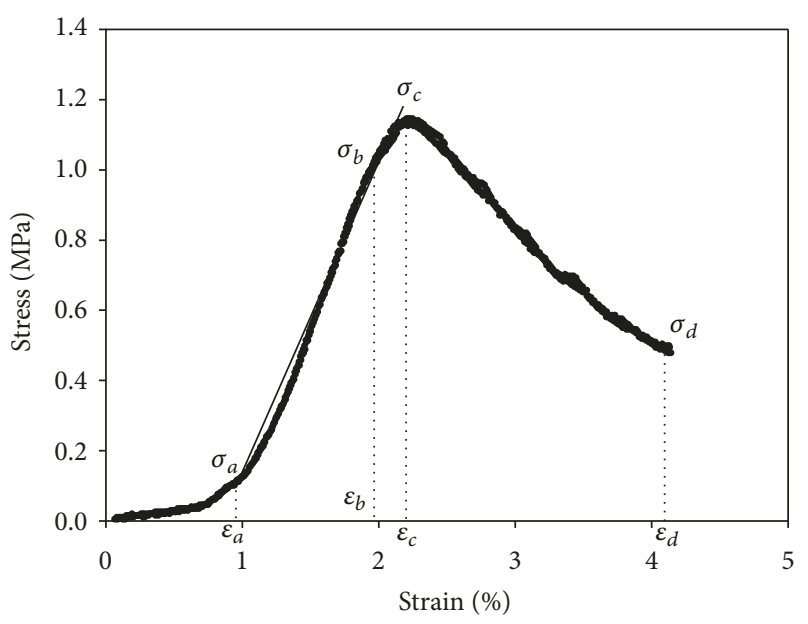

FIgURE 3: Stress-strain curve of CGB.

the CGB. At the beginning of the mixing process, the large number of pores in the particles took up water. The water was constantly consumed to take part in the chemical reaction or to evaporate, leaving the empty space preserved to be filled with more products. This led to the variation of the pore structure in the CGB with the curing time. This variation of the pore structure can influence the resistivity and $\mathrm{AE}$ characteristics under loading conditions.

The products filled the large capillary pores and some of the middle pores. The gel micropores represent the interlayer pores between the C-S-H gels, which would not affect the permeability and strength. The content of gel micropores increased with the increasing $\mathrm{C}-\mathrm{S}-\mathrm{H}$ gel content and the increasing curing time.

\subsection{Deformation Behavior of CGB under Axial Loading.}

The analysis of the resultant stress-strain curves (see Figure 3) in the compression of the CGB indicated that the CGB compression process can be roughly divided into the following stages (corresponding to the fracture changes of the sample presented in Figures 4(a)-4(f)): (1) pore closure stage $\left(0 \sim \mathcal{E}_{a}\right)$ (see Figure $\left.4(\mathrm{a})\right)$ : certain of the larger diameter pores were closed under the compression, and the curve exhibited a nonlinear change; (2) reversible elastic deformation stage $\left(\varepsilon_{a} \sim \varepsilon_{b}\right)$ (see Figure $\left.4(\mathrm{~b})\right)$ : the CGB experienced elastic deformation under the compression, and the curve exhibited a nearly linear change; few cracks occurred at the surface of the CGB sample; (3) unstable fracture development stage $\left(\varepsilon_{b} \sim \varepsilon_{c}\right)$ (see Figures $4(\mathrm{c})$ and $4(\mathrm{~d})$ ): at this stage, the CGB underwent irreversible plastic deformation, and the microcracks were continuously generated, expanded, and combined; (4) residual deformation stage (see Figures 4(e) and $4(\mathrm{f})$ ): the cracks are transmitted from the microscale to the macroscale at the surface of the CGB sample. The direction of the crack growth is parallel to the direction of the axial loading, and the range of the crack development mainly occurred at the bottom of the sample.

Figure 5 shows the stress-strain curves at 1-day, 3-day, and 7 -day curing times. With the increasing time, the values of the compressive strength are $0.68 \mathrm{MPa}, 1.27 \mathrm{MPa}$, and $1.45 \mathrm{MPa}$ and the values of the elasticity modulus are $81.87 \mathrm{MPa}$, 91.88 $\mathrm{MPa}$, and $97.14 \mathrm{MPa}$ for 1 day, 3 days, and 7 days, respectively.

3.3. Microscopic Properties of CGB under Loading Conditions. When the stress reaches $\sigma_{a}$, the bonding between the gangue and CGB paste appears to be relatively tight, and the interfacial transition zone (ITZ) is mainly filled with columnar and petal-shaped chemical reaction products (as Figure 6 shows). When the stress reaches $\sigma b$, crack tension occurs between the gangue and the paste. Microobservation showed that the needle-shaped, columnar products exist as ruptured fragments at the surface of the crack. The crack passes through the ITZ along the ITZ strike direction. As illustrated in Figure 7, when the stress reaches the yield limit under axial loading conditions, the primary crack forms in the position of the major ITZ, which exhibits a larger gangue and paste contact surface. The primary crack then expands along the major strike direction.

Three types of crack formed in the CGB sample under the axial loading condition: the expansion and dislocation of the ITZ between the paste and gangue, the internal paste, and the internal gangue. Figure 7 presents the three types of crack. AE is a physical phenomenon in which part of the strain energy under loading is released by transient elastic waves in the process of crack propagation and expansion in the CGB [30]. The application of mechanical loading on CGB generates various electrical currents due to the formation and propagation of microfractures for providing flowing channels for the pore solution [31].

3.4. Stress-Strain-Resistivity-AE Signature. The AE ring counts are used to analyze the $\mathrm{AE}$ signature. $\mathrm{AE}$ ring counts, which reflect the number of oscillations exceeding the threshold signal, reflect the signal intensity and are also used to evaluate the AE activity. The CGB test results with different curing times were used to analyze the changes in the CGB stress-strain-resistivity-AE ring counts under loading conditions. The relationship between the $\mathrm{AE}$ ring counts and the CGB damage was analyzed to explain the resistivity variation. The deformation stage of the CGB is divided into four periods.

(1) The Compaction and Consolidation of Pores and Microcracks. In this stage, the $\mathrm{AE}$ signal was relatively weak, leading the ring counts to decrease because the microcrack and pore closure make the surface contact and slip. The character of the AE signals is similar to that of the original pore and fissure compaction of the rock. The resistivity also decreased, as influenced by the pore structure permeability and pore solution. On one hand, the original pores and microcracks are connected under the loading condition to improve the pore structure permeability; on the other hand, the effect of the pore surface tension is weak, and the ability of absorbing water is reduced, which leads the rate of pore solution flow in the pore structure to significantly increase. As the curing time increases, the stage of pore compaction shortens and the $\mathrm{AE}$ ring counts increase. This is because the reduction of the water content and porosity in the CGB cause an improvement 


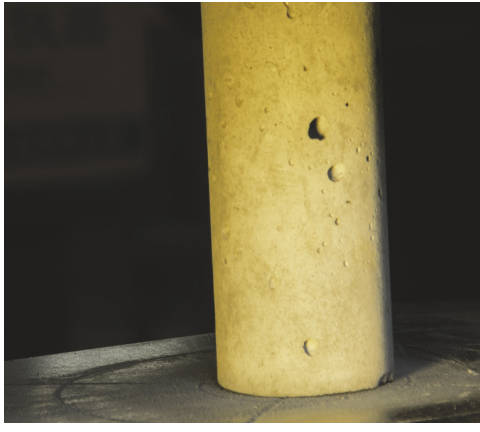

(a)

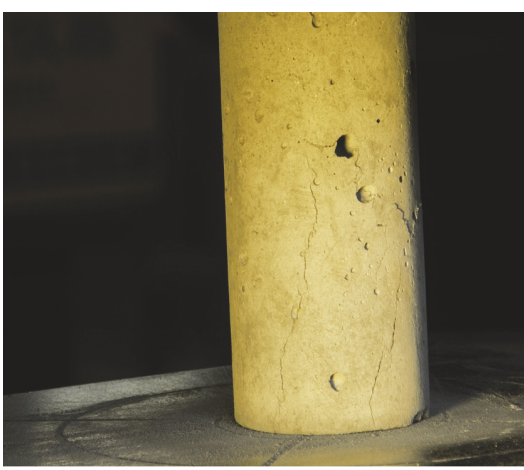

(d)

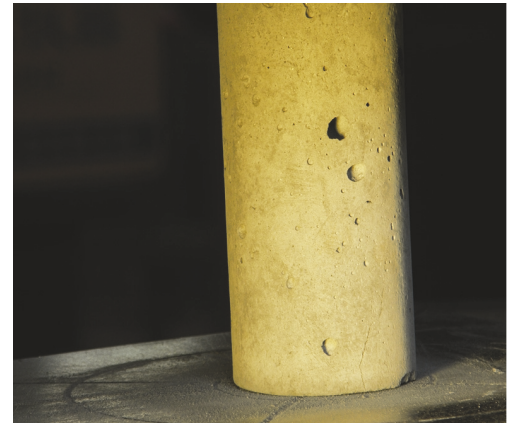

(b)

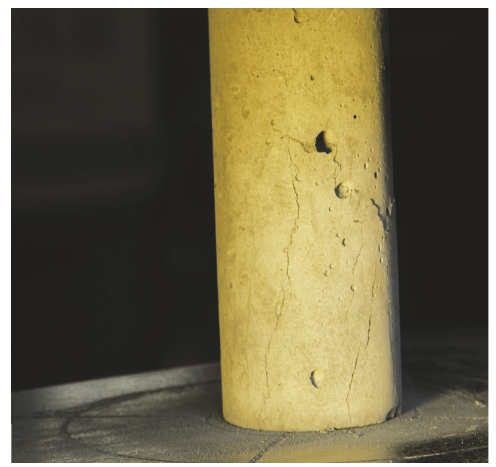

(e)

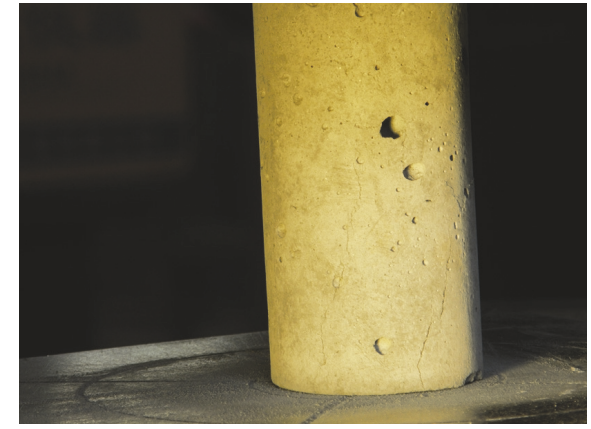

(c)

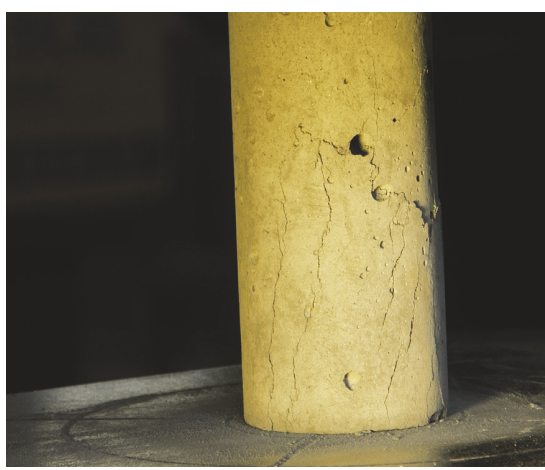

(f)

FIGURE 4: Fracture changes in the process of specimen compression.

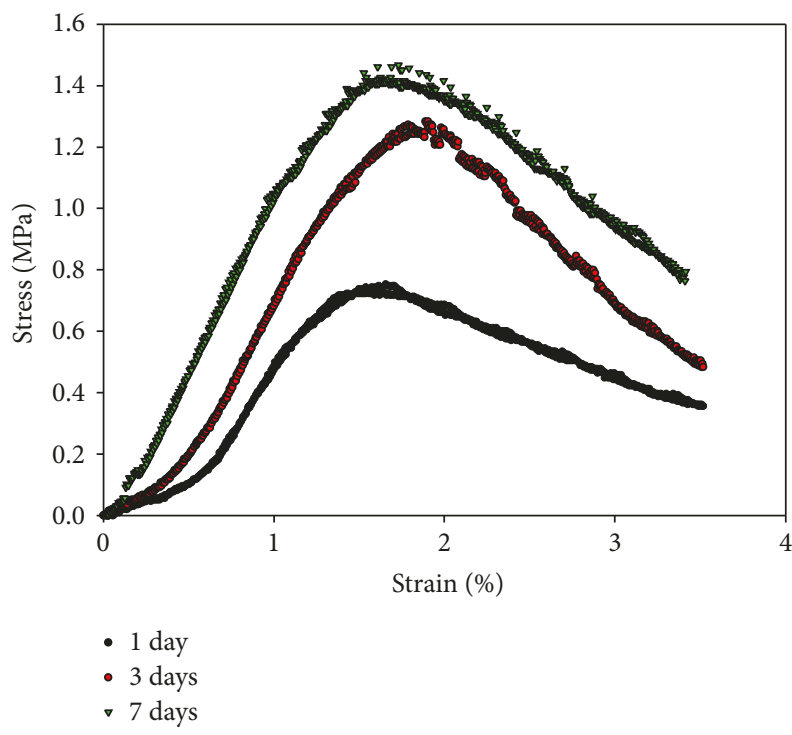

FIGURE 5: Stress-strain curve at different curing times.

in the fragility, corresponding to the increase in the $\mathrm{AE}$ signals.

It was also demonstrated in Figure 8 that the rate of decline of the resistivity decreased with the increasing curing time at the stage of pore compaction. It can be explained that the pore solution obtained a quick flowing speed through the CGB specimen under the axial pressure due to the large quantity of pore solution and the connected pore structure at the early curing time.

(2) The Elastic Deformation Stage. The AE signals slightly increase but maintain a low level, as the fly ash, gangue, cement, and hydration product particles contact each other and cause friction. The resistivity curve further drops, and as the previous stage extends, the channels are constantly broken through to enhance the mobility of the pore solution in the pore structure. These particles release more active ions into the pore solution, which increases the concentration of pore solution.

As the curing time increases, the AE signal improves. It can be concluded that, at the earlier period, the higher water content effectively absorbs the AE energy from the interparticle friction. The rate of resistivity is reduced because the CGB specimen contains higher porosity and water content, which leads the resistivity to be more sensitive to the pressure.

(3) The Plastic Deformation to Fracture Unstable Development. The AE signals gradually increase and reach a peak as the stress reaches its maximum value. In this period, the extent of the cracks reaches its peak and the sample of CGB is completely destroyed, leading to a sudden abrupt release of AE energy. However, the maximum ring counts exhibit an obvious hysteresis, corresponding to peak of stress. The pore solution absorbs a part of the AE energy and slows down the time needed for the AE signals to be transmitted to the probe. With the increasing curing time, the hysteresis weakens. This phenomenon is similar to the AE character of water-saturated sandstone, as was presented in [32]. 

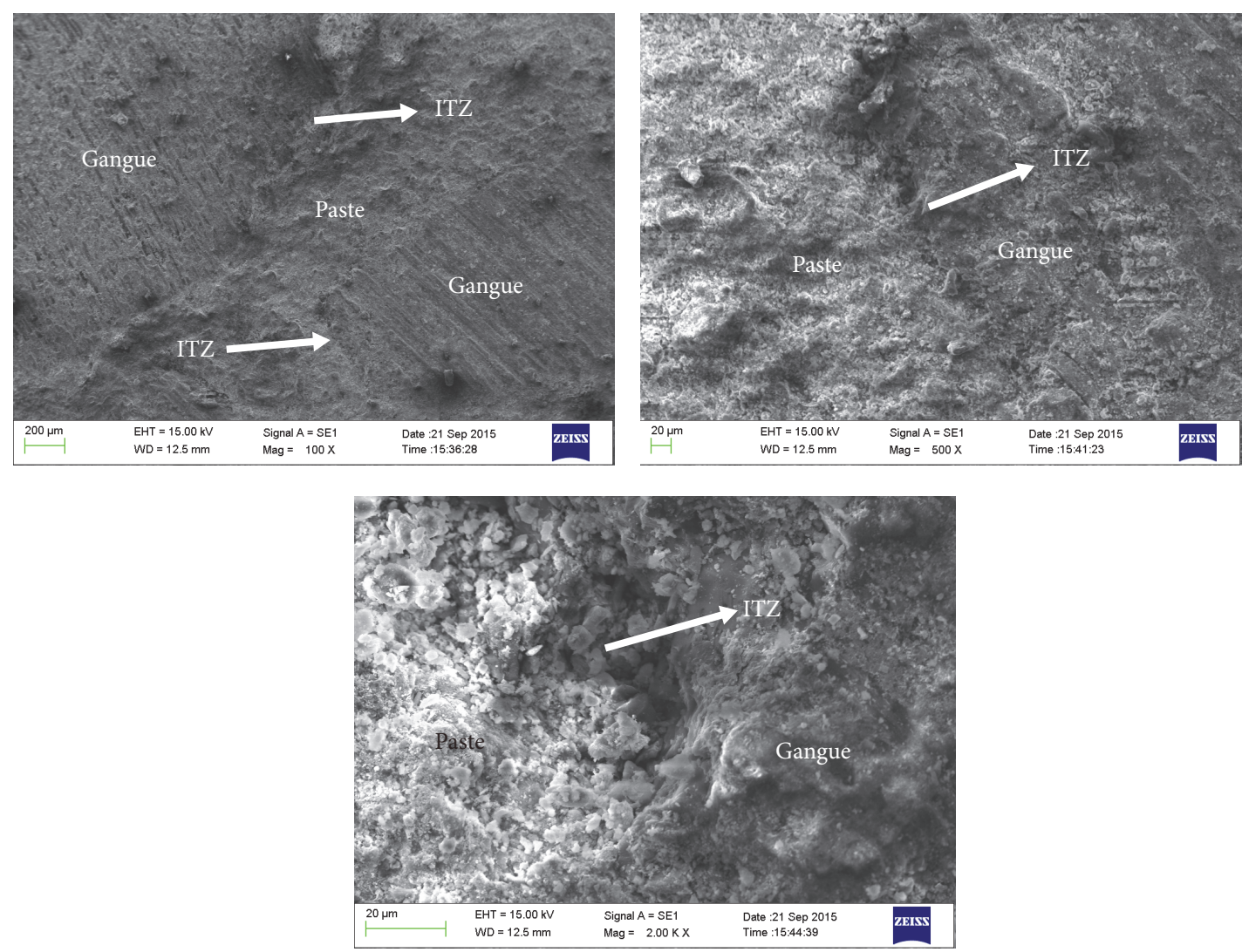

FigURE 6: SEM photos of CGB sample under $\sigma_{a}$.
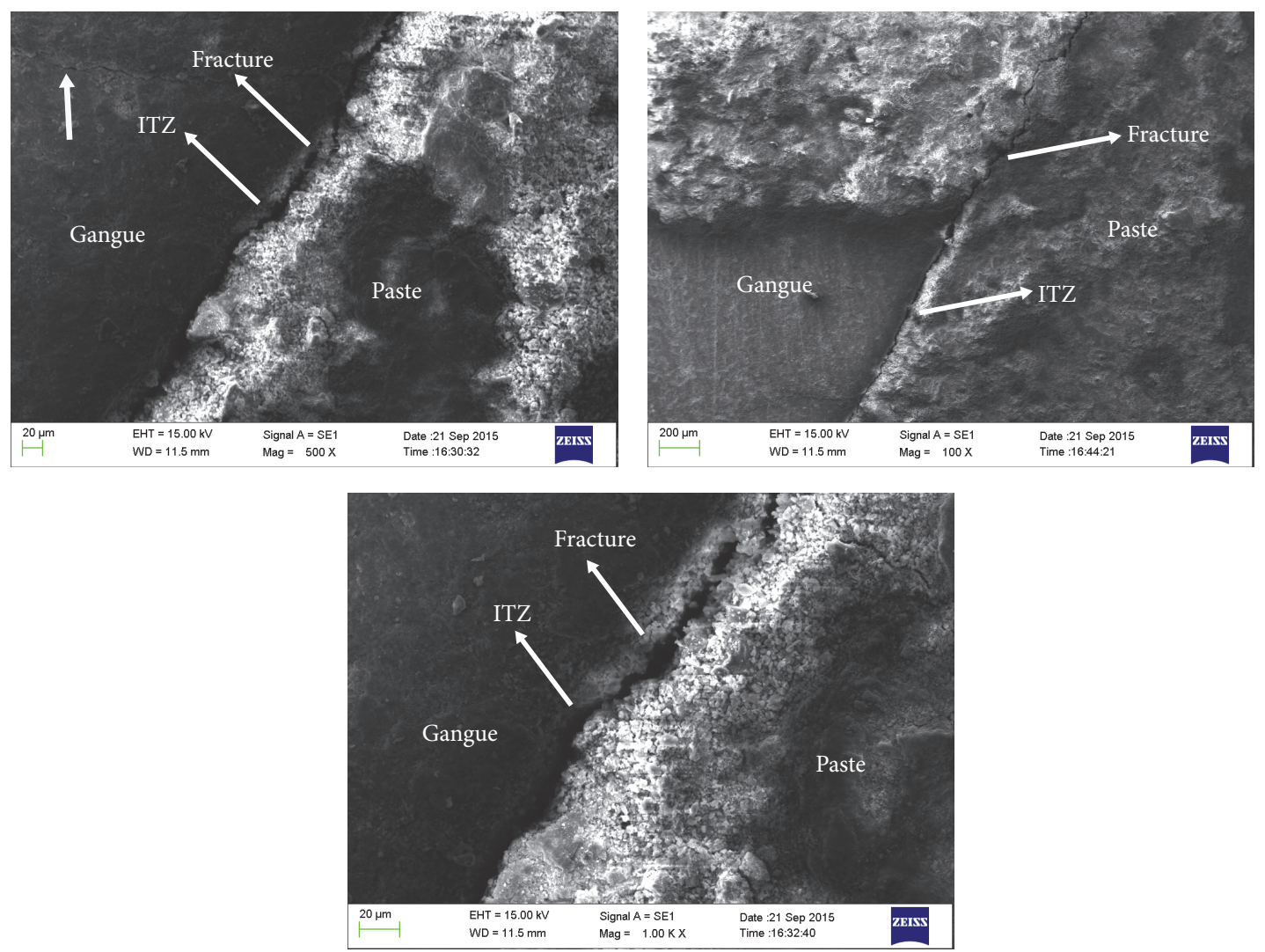

FIGURE 7: SEM photos of CGB sample under $\sigma_{b}$. 


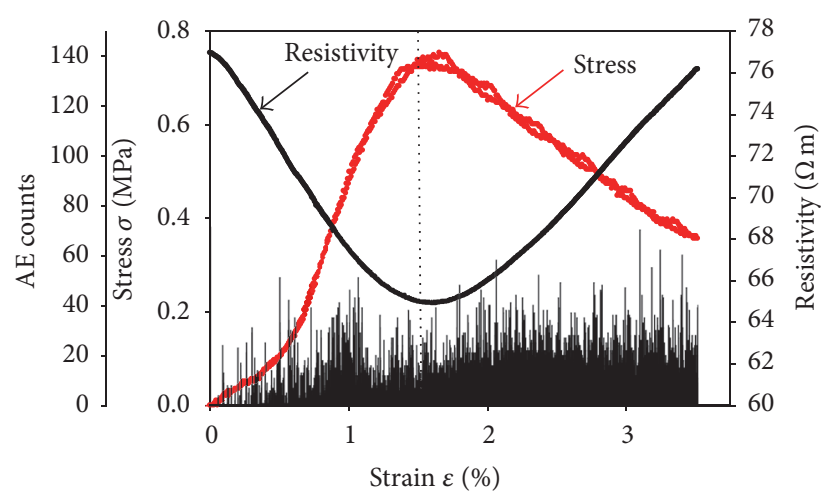

(a) At 1-day curing time

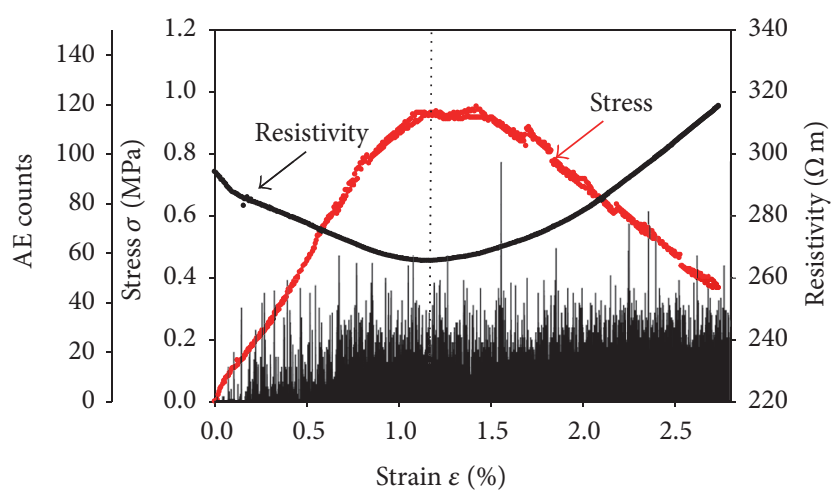

(b) At 3-day curing time

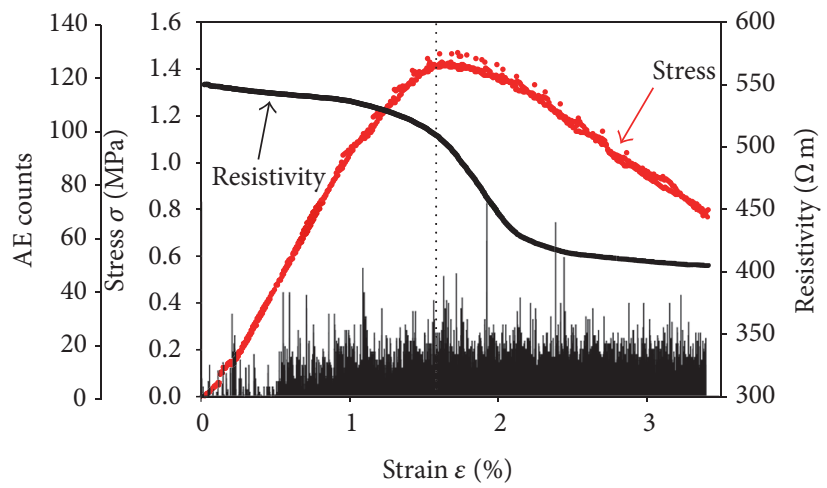

(c) At 7-day curing time

FIGURE 8: Relational graph of CGB stress, resistivity, and AE counts.

The resistivity value reaches its minimum at $64.8 \Omega \cdot \mathrm{m}$ for 1 day and $268 \Omega \cdot \mathrm{m}$ for 3 days. The resistivity value continually drops for 7 days at a rapid rate, which is different from the experimental results for 1 day and 3 days. It can be determined that the larger volume of products fills in the pore and ITZ owing to the more sufficient chemical reaction in 7 days, and the tortuous channel could hinder the flowing of the pore solution in the CGB sample. When the stress nearly reaches the top, the adsorption water is turned into free water in the pores under the pore pressure. The development of cracks leads to the formation of cut-through flow channels.

(4) The CGB Failure Stage. The AE ring count maintains a high value. In the later failure period, there is a rather strong AE signal, which can be attributed to the detached bulk generating wide-range violent gliding along the plane of fracture.

The failure process of CGB is characterized by crack initiation, propagation, and coalescence with associated damage and evolution. For the 1-day and 3-day curing times, the macroplane of disruption in the failure process mainly happened in the middle position of the CGB sample, as shown in Figure 9(a). The tension crack located in the ITZ, gangue, and paste continually expanded, was dislocated, and slipped, and the fragments of the gangue and paste blocked a part of the gallery to prevent the pore solution from flowing into the pore structure of the CGB. In addition, a certain width crack has a negative effect on the storage of the pore solution, which rapidly runs off under pressure, and as the media influences the electric current transport, the resistivity of the CGB decreases with the decreasing stress.

For the 7-day curing time, there is less pore solution contained in the pores due to evaporation and participation in the hydration and pozzolanic reaction. After the peak of the stress, the pore solution is discharged from the broken pores. The crack forms a cut-through channel from top to bottom, as shown in Figure 9(b), which improves the transport of electricity. Consequently, the resistivity declines until reaching a stable level with the decreasing stress.

3.5. Relationship between Stress and Resistivity. Figure 10 shows the relationship between the stress and resistivity before and after the stress peak at 1 day (Figures 10(a) and $10(\mathrm{~b})), 3$ days (Figures 10(c) and 10(d)), and 7 days (Figures 10(e) and 10(f)). In the current study, the results of the resistivity and stress of the CGB samples were analyzed using the method of least-squares regression. It was found that there is a quadratic relationship with a high correlation coefficient between the stress and resistivity for the CGB 


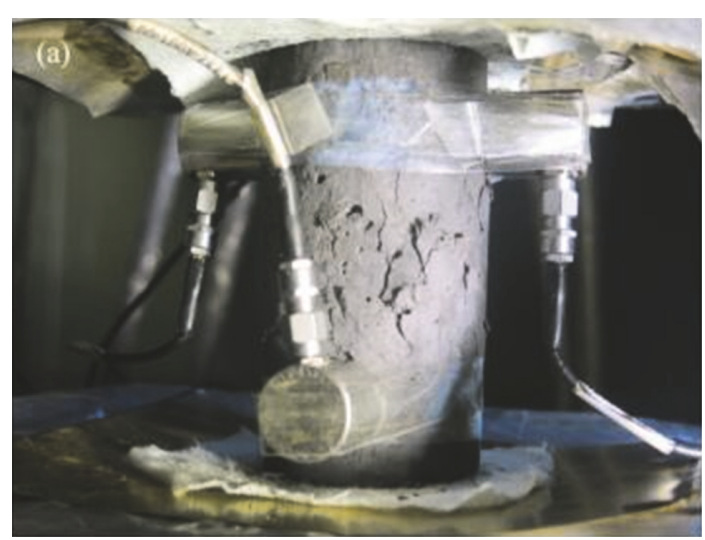

(a)

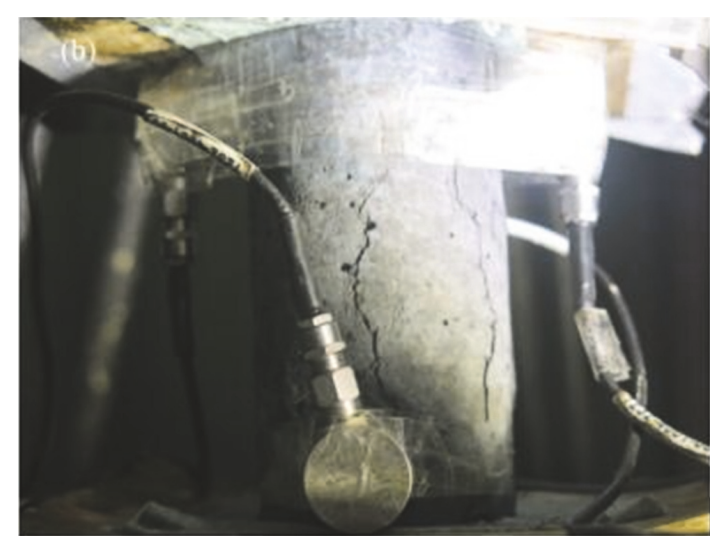

(b)

FIGURE 9: Photos of CGB samples after failure: (a) CGB sample at 1 day and (b) CGB sample at 7 days.

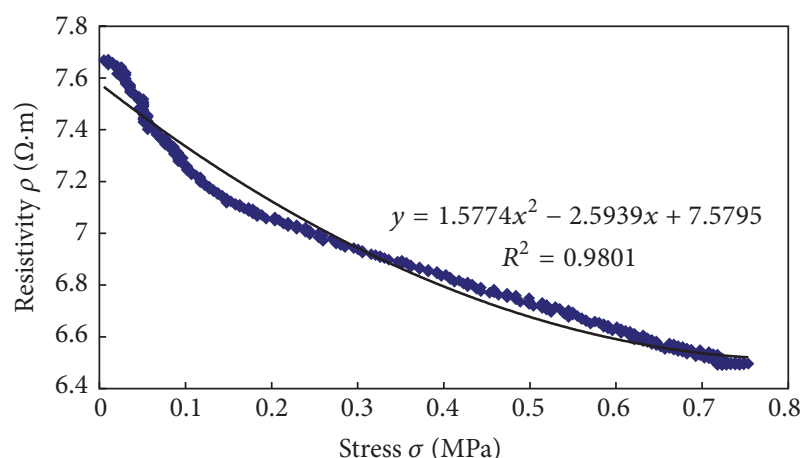

(a) Before the peak of stress

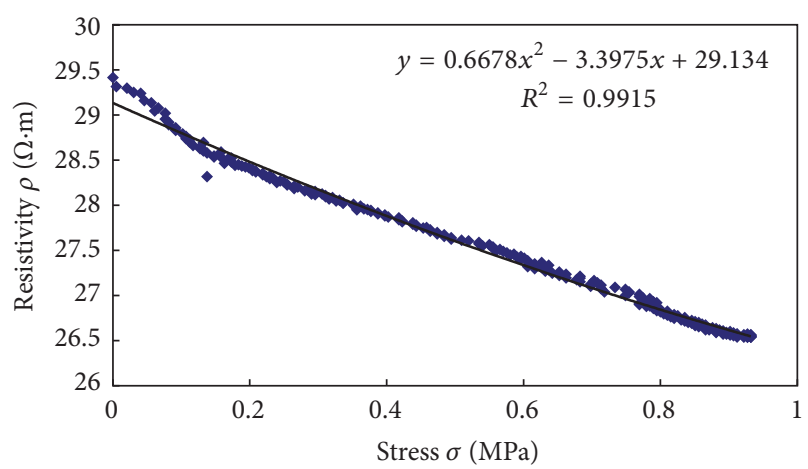

(c) Before the peak of stress

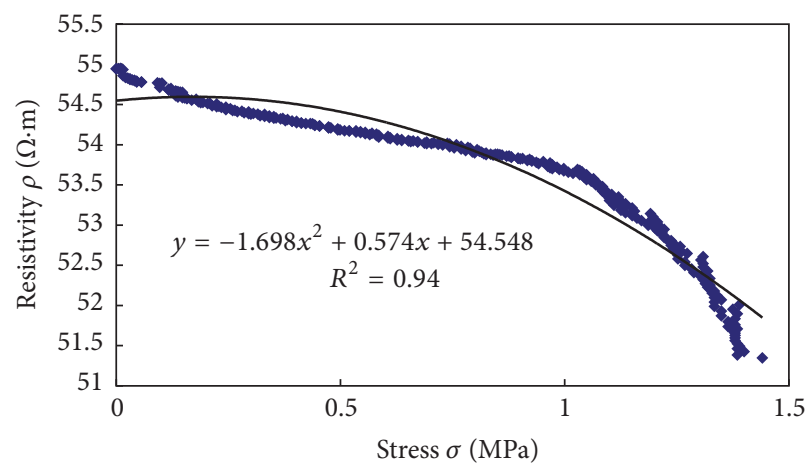

(e) Before the peak of stress

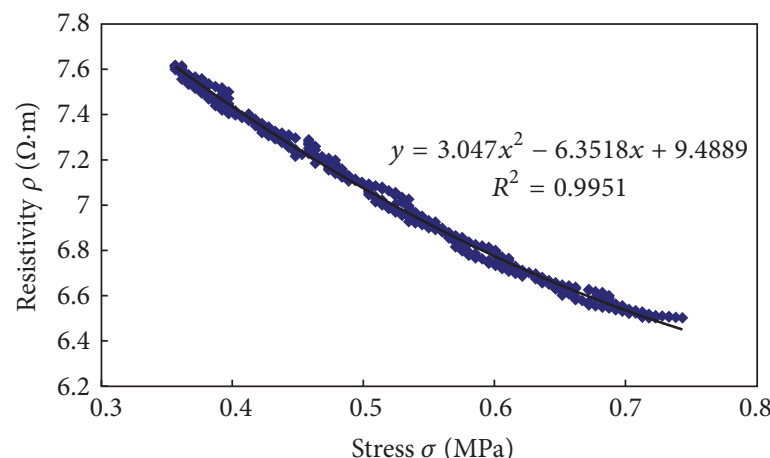

(b) After the peak of stress

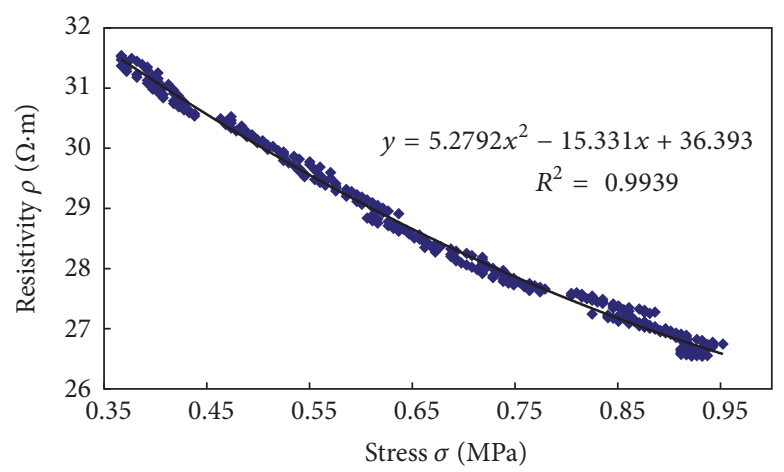

(d) After the peak of stress

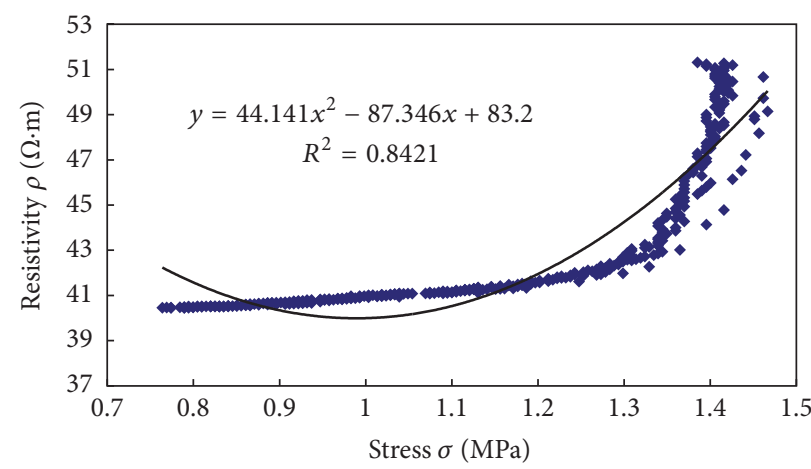

(f) After the peak of stress

FIGURE 10: Relationship between stress and resistivity before and after the stress peak at 1 day (a, b), 3 days (c, d), and 7 days (e, f). 
samples before and after the stress peak at different curing times. The following general equations were found. A general expression is given in (7).

$$
\begin{aligned}
Y & =1.5774 x^{2}-2.5939 x+7.5795 \\
R^{2} & =0.9801
\end{aligned}
$$

(at 1 day before the peak of stress)

$Y=3.047 x^{2}-6.3518 x+9.4889$,

$R^{2}=0.9951$,

(at 1 day after the peak of stress)

$$
\begin{aligned}
Y & =0.6678 x^{2}-3.3975 x+29.134, \\
R^{2} & =0.9915,
\end{aligned}
$$

(at 3 days before the peak of stress)

$$
Y=5.2792 x^{2}-15.331 x+36.393
$$$$
R^{2}=0.9939,
$$

(at 3 days after the peak of stress)

$$
\begin{aligned}
Y & =-1.698 x^{2}+0.574 x+54.548 \\
R^{2} & =0.94
\end{aligned}
$$

(at 7 days before the peak of stress)

$$
\begin{aligned}
Y & =44.141 x^{2}-87.346 x+83.2 \\
R^{2} & =0.8421
\end{aligned}
$$

(at 7 days after the peak of stress)

$$
Y=a x^{2}+b x+c \quad \text { (general expression), }
$$

where $Y$ is the electrical resistivity of the CGB at different curing times in $\Omega \cdot m ; x$ is the stress of the CGB after and before the stress peak at different curing times in $\mathrm{MPa}$; and $a, b$, and $c$ are the practical parameters, which vary after and before the stress peak and with the curing time. A wider range of properties of the CGB will be needed to obtain more practical parameters, $a, b$, and $c$, based on more tests in further study. The resistivity of CGB was affected by ions concentration of pore solution and the flowing channel; the channel consists of the pore structure and the crack in the CGB. When the CGB samples were under the uniaxial loading, resistivity value happened to change due to the variation of pore structure and crack as the stress increased. Therefore, there is a quadratic function relationship between stress and resistivity for CGB samples of different curing time during the uniaxial loading condition. Accordingly, these quadratic function models can be used to estimate the stress of the CGB body exerted by the overlying strata using resistivity data.
3.6. Stress-Strain-AE Cumulative Energy. The relational graphs of the CGB stress and AE cumulative energy at different curing times are presented in Figure 11. The AE cumulative energy increases with the axial strain for all of the CGB samples. The stress-strain-AE cumulative energy curve is approximately divided into 2 linear stages with the stress peak as the boundary; the slope of the curve is relatively low before the peak of the stress and relatively high thereafter. The original pore compaction and elastic deformation lead to the weak AE signals, which explain the relative slower increase in the AE cumulative energy before the peak of the stress. The expansion, dislocation, and slippage of the weak structural plane in the CGB sample lead to the violent AE signals, which explain the more rapid increase in the $\mathrm{AE}$ cumulative energy after the peak of the stress.

The slope of the AE cumulative energy gradually increases with the increasing curing time before the peak of the stress. For the shorter curing time, the higher water content could attract part of the AE energy generated from the original pore and fissure compaction. For the shorter curing time, the CGB transforms from a plastic material to a fragile material, and the original pore and fissure compaction could give rise to the greater amount of AE energy.

The slope of the AE cumulative energy curve gradually decreases with the increasing curing time after the peak of the stress. For the shorter cuing time, the lower degree leads to producing less gel products, which is inadequate for bonding with gangues. Therefore, many cracks are distributed in the CGB sample. The cracks of the CGB sample expand in irregular directions in the middle of the sample under the loading condition, as is presented in Figure 9(a). The slope of the AE cumulative energy is large due to the larger numbers of AE energy sources and fracture planes. For the longer curing time, the improved degree of CGB hardening leads to crack extension until achieving connection along the two obvious planes of fracture in the axial direction, which produces less AE energy and a lower variation in the AE cumulative energy, as is presented in Figure 9(b). Furthermore, the difference in the slopes of the AE cumulative energy curve before and after the peak of the stress decreases with the increasing curing time.

\section{Conclusions}

The changes in the $\mathrm{CGB}$ resistivity and $\mathrm{AE}$ character for various curing times under the loading condition were analyzed, and the conclusions were as follows:

(1) The changes in the AE ring counts seem to be similar for the 1-day, 3-day, and 7-day CGB samples. In the earlier loading period, the AE signal was weak, but, with the increasing stress, the AE signals are gradually enhanced. However, the peak of the stress is inconsistent with the maximum $\mathrm{AE}$ ring count due to the hysteresis of the elastic wave diffusion. The phenomenon of hysteresis gradually decreases. At the residual deformation stage, there exist other 


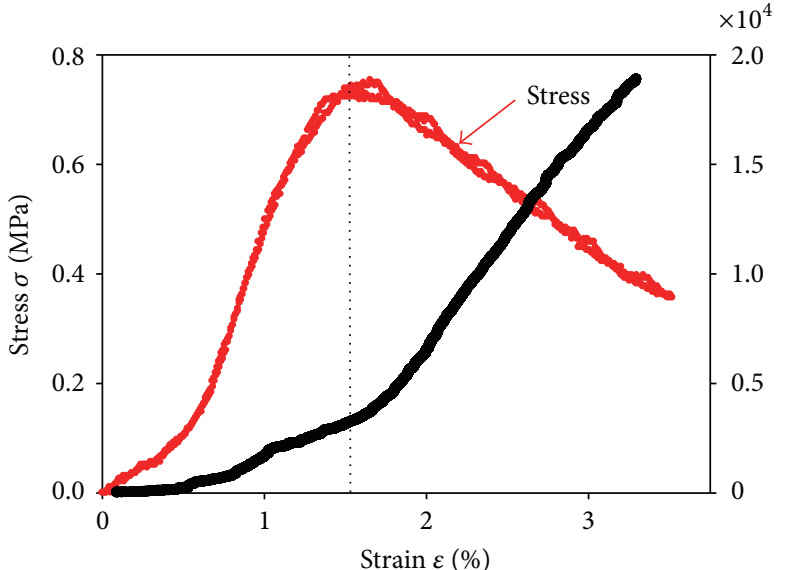

(a) At 1-day curing time

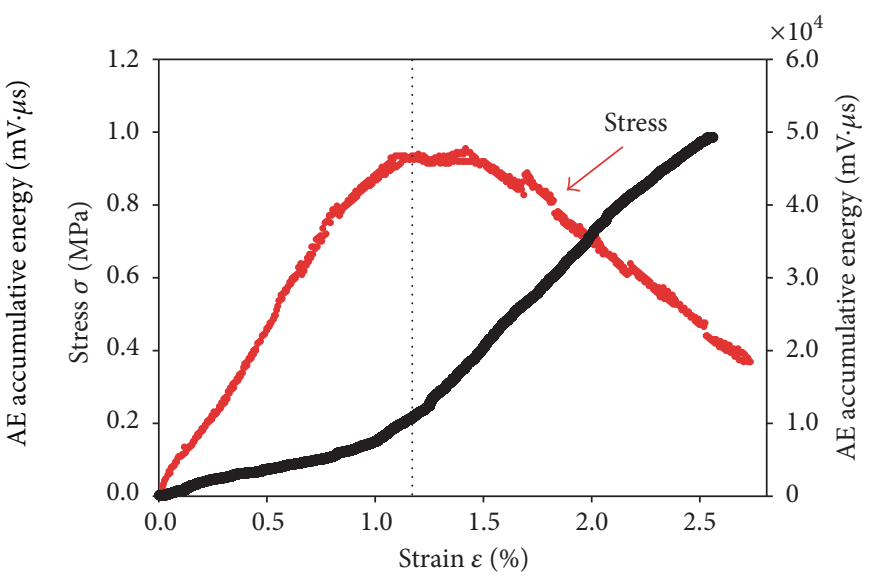

(b) At 3-day curing time

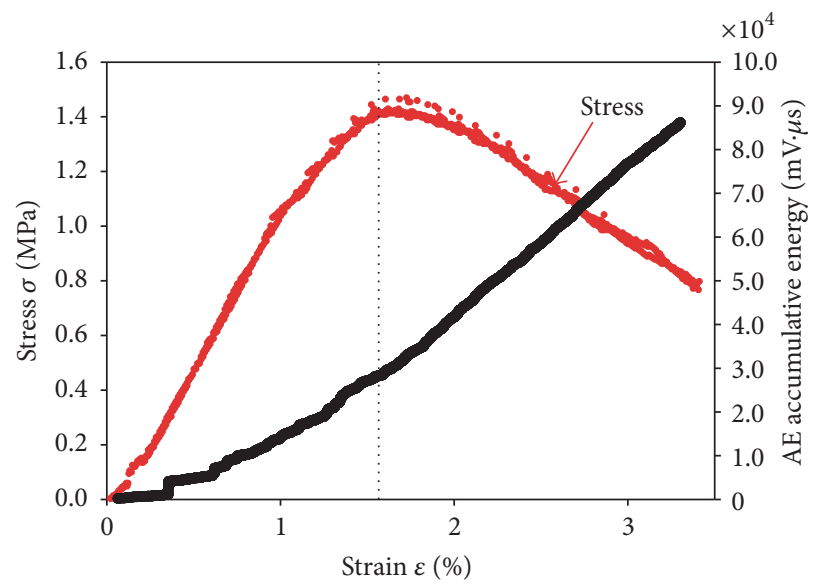

(c) At 7-day curing time

FIGURE 11: Relational graph of CGB stress and AE cumulative energy.

relative $\mathrm{AE}$ signals. For the 1-day and 3-day curing times, the resistivity curve of the CGB first decreases and then increases under the loading condition, with the minimum value corresponding to the peak of the stress. At the 7-day curing time, the resistivity curve shows a declining trend, and the fast rate of the resistivity variation corresponds to the peak of the stress.

(2) The AE energy curve is divided into two approximately straight lines with the stress peak as the boundary. The slope of the AE energy curve increases with the increasing curing time before the peak of stress, and it decreases with the increasing curing time after the peak of stress.

(3) There exists a quadratic relationship with a high correlation coefficient between the stress and resistivity for the CGB samples before and after the stress peak for different curing times. Accordingly, these quadratic models can be used to estimate the stress on the CGB body exerted by the overlying strata using resistivity data.

(4) When the stress reaches the yield point, crack tension occurs between the gangue and the paste. Microobservation shows that the needle-shaped, columnar products exist as ruptured fragments at the surface of the crack. The ITZ crack expands along the ITZ strike direction.

\section{Conflicts of Interest}

The authors declare that they have no conflicts of interest.

\section{Acknowledgments}

This work was financially supported by the National Natural Science Foundation of China (51174142 and 51422404), the Key Scientific and Technological Coal Projects of Shanxi Province in 2014 (MQ2014-12), and the Applied Basic Research Programs of Shanxi Province (201601D021089). 


\section{References}

[1] Z. F. Bian, X. X. Miao, S. G. Lei, S.-E. Chen, W. F. Wang, and S. Struthers, "The challenges of reusing mining and mineralprocessing wastes," Science, vol. 337, no. 6095, pp. 702-703, 2012.

[2] D. Hewitt, S. Allard, and P. Radziszewski, "Pipe lining abrasion testing for paste backfill operations," Minerals Engineering, vol. 22, no. 12, pp. 1088-1090, 2009.

[3] X. Zhu, G. Guo, J. Zha, T. Chen, Q. Fang, and X. Yang, "Surface dynamic subsidence prediction model of solid backfill mining," Environmental Earth Sciences, vol. 75, no. 12, article 1007, 2016.

[4] J. Zhang, Q. Zhang, Q. Sun, R. Gao, D. Germain, and S. Abro, "Surface subsidence control theory and application to backfill coal mining technology," Environmental Earth Sciences, vol. 74, no. 2, pp. 1439-1448, 2015.

[5] W. Sun, A. Wu, K. Hou, Y. Yang, L. Liu, and Y. Wen, "Real-time observation of meso-fracture process in backfill body during mine subsidence using X-ray CT under uniaxial compressive conditions," Construction and Building Materials, vol. 113, pp. 153-162, 2016.

[6] W. Sui, D. Zhang, Z. C. Cui, Z. Wu, and Q. Zhao, "Environmental implications of mitigating overburden failure and subsidences using paste-like backfill mining: a case study," International Journal of Mining, Reclamation and Environment, vol. 29, no. 6, pp. 521-543, 2015.

[7] S. Chen, H. Wang, J. Zhang, H. Xing, and H. Wang, "Low-strength similar materials for backfill mining: insight from experiments on components and influence mechanism," Geotechnical Testing Journal, vol. 38, no. 6, pp. 929-935, 2015.

[8] Y. Fan, "Research on KAISER effect during closing period of rock cracks under uniaxial loading," Chinese Journal of Rock Mechanics and Engineering, vol. 20, no. 6, pp. 793-796, 2001.

[9] X.-G. Yin, "Contrast study on the acoustic emission characteristics of compressive rock and concrete through experiment," Journal of Sichuan University (Engineering Science Edition), vol. 42, no. 2, pp. 82-87, 2010.

[10] J. Xu, S. Li, X. Tang, Y. Tao, and Y. Jiang, "Influential factors of acoustic emission location experiment of rock under uniaxial compression," Chinese Journal of Rock Mechanics and Engineering, vol. 27, no. 4, pp. 765-772, 2008.

[11] V. Saltas, I. Fitilis, and F. Vallianatos, "A combined complex electrical impedance and acoustic emission study in limestone samples under uniaxial loading," Tectonophysics, vol. 637, pp. 198-206, 2014.

[12] V. Saltas, V. Chatzistamou, D. Pentari et al., "Complex electrical conductivity measurements of a KTB amphibolite sample at elevated temperatures," Materials Chemistry and Physics, vol. 139, no. 1, pp. 169-175, 2013.

[13] H. Ji, H. Wang, S. Cao, Z. Hou, and Y. Jin, "Experimental research on frequency characteristics of acoustic emission signals under uniaxial compression of granite," Chinese Journal of Rock Mechanics and Engineering, vol. 31, no. 1, pp. 2900-2905, 2012.

[14] Q. Guo, B. Xi, Z. Li, X. Zheng, J. Tian, and H. Zhu, "Experimental research on relationship between frequency characteristics of acoustic emission and strength parameter in concrete," Journal of Central South University (Science and Technology), vol. 46, no. 4, pp. 1482-1488, 2015.

[15] J.-Q. Hao, R. Feng, J.-G. Zhou, S.-Q. Qian, and J.-T. Gao, "Study on the mechanism of resistivity changes during rock cracking," Acta Geophysica Sinica, vol. 45, no. 3, pp. 434-442, 2002.
[16] G. Chen and Y. Lin, "Stress-strain-electrical resistance effects and associated state equations for uniaxial rock compression," International Journal of Rock Mechanics and Mining Sciences, vol. 41, no. 2, pp. 223-236, 2004.

[17] P. Chen, E.-Y. Wang, and Y.-F. Zhu, "Experimental study on resistivity variation regularities of loading coal," Journal of the China Coal Society, vol. 38, no. 4, pp. 548-553, 2013.

[18] S. Li, X. Xu, Z. Liu et al., "Electrical resistivity and acoustic emission response characteristics and damage evolution of sandstone during whole process of uniaxial compression," Chinese Journal of Rock Mechanics and Engineering, vol. 33, no. 1, pp. 14-23, 2014.

[19] Y.-H. Wang, Y.-F. Liu, and H.-T. Ma, "Changing regularity of rock damage variable and resistivity under loading condition," Safety Science, vol. 50, no. 4, pp. 718-722, 2012.

[20] F. Vallianatos, P. Benson, P. Meredith, and P. Sammonds, "Experimental evidence of a non-extensive statistical physics behaviour of fracture in triaxially deformed Etna basalt using acoustic emissions," EPL, vol. 97, no. 5, Article ID 58002, 2012.

[21] F. Vallianatos, G. Michas, P. Benson, and P. Sammonds, "Natural time analysis of critical phenomena: the case of acoustic emissions in triaxially deformed Etna basalt," Physica A: Statistical Mechanics and Its Applications, vol. 392, no. 20, pp. 5172-5178, 2013.

[22] T. Qi, G. Feng, Y. Zhang, J. Guo, and Y. Guo, "Effects of fly ash content on properties of cement paste backfilling," Journal of Residuals Science and Technology, vol. 12, no. 3, pp. 133-141, 2015.

[23] T. Qi, G. Feng, Y. Guo et al., "Experimental study on the changes of coal paste backfilling material performance during hydration process," Journal of Mining and Safety Engineering, vol. 32, no. 1, pp. 42-48, 2015.

[24] L.-J. Ouyang, Z.-D. Lu, Y.-L. Zhao, and H.-B. Lv, "Setting of acoustic emission detecting parameters in concrete structure," Journal of Chongqing Jianzhu University, vol. 30, no. 5, pp. 3741, 2008.

[25] R. A. Cook and K. C. Hover, "Mercury porosimetry of hardened cement pastes," Cement and Concrete Research, vol. 29, no. 6, pp. 933-943, 1999.

[26] E. J. Reardon, "Problems and approaches to the prediction of the chemical composition in cement/water systems," Waste Management, vol. 12, no. 2-3, pp. 221-239, 1992.

[27] K. Aligizaki, Pore Structure of Cement-Based Materials, Taylor \& Francis, New York, NY, USA, 2006.

[28] P. K. Metha and P. J. M. Monterio, Concrete, Microstructure, Properties and Materials, McGraw-Hill, London, UK, 2006.

[29] J. Kaufmann, R. Loser, and A. Leemann, "Analysis of cementbonded materials by multi-cycle mercury intrusion and nitrogen sorption," Journal of Colloid and Interface Science, vol. 336, no. 2, pp. 730-737, 2009.

[30] A. Carpinteri, G. Lacidogna, F. Accornero, A. C. Mpalaskas, T. E. Matikas, and D. G. Aggelis, "Influence of damage in the acoustic emission parameters," Cement and Concrete Composites, vol. 44, pp. 9-16, 2013.

[31] C. Stergiopoulos, I. Stavrakas, G. Hloupis, D. Triantis, and F. Vallianatos, "Electrical and Acoustic Emissions in cement mortar beams subjected to mechanical loading up to fracture," Engineering Failure Analysis, vol. 35, pp. 454-461, 2013.

[32] Q.-L. Yao, X.-H. Li, L.-H. He, and J. Zhou, "Strength deterioration and acoustic emission characteristics of water-bearing sandstone in uniaxial compressive experiment," Journal of Mining and Safety Engineering, vol. 30, no. 5, pp. 717-722, 2013. 

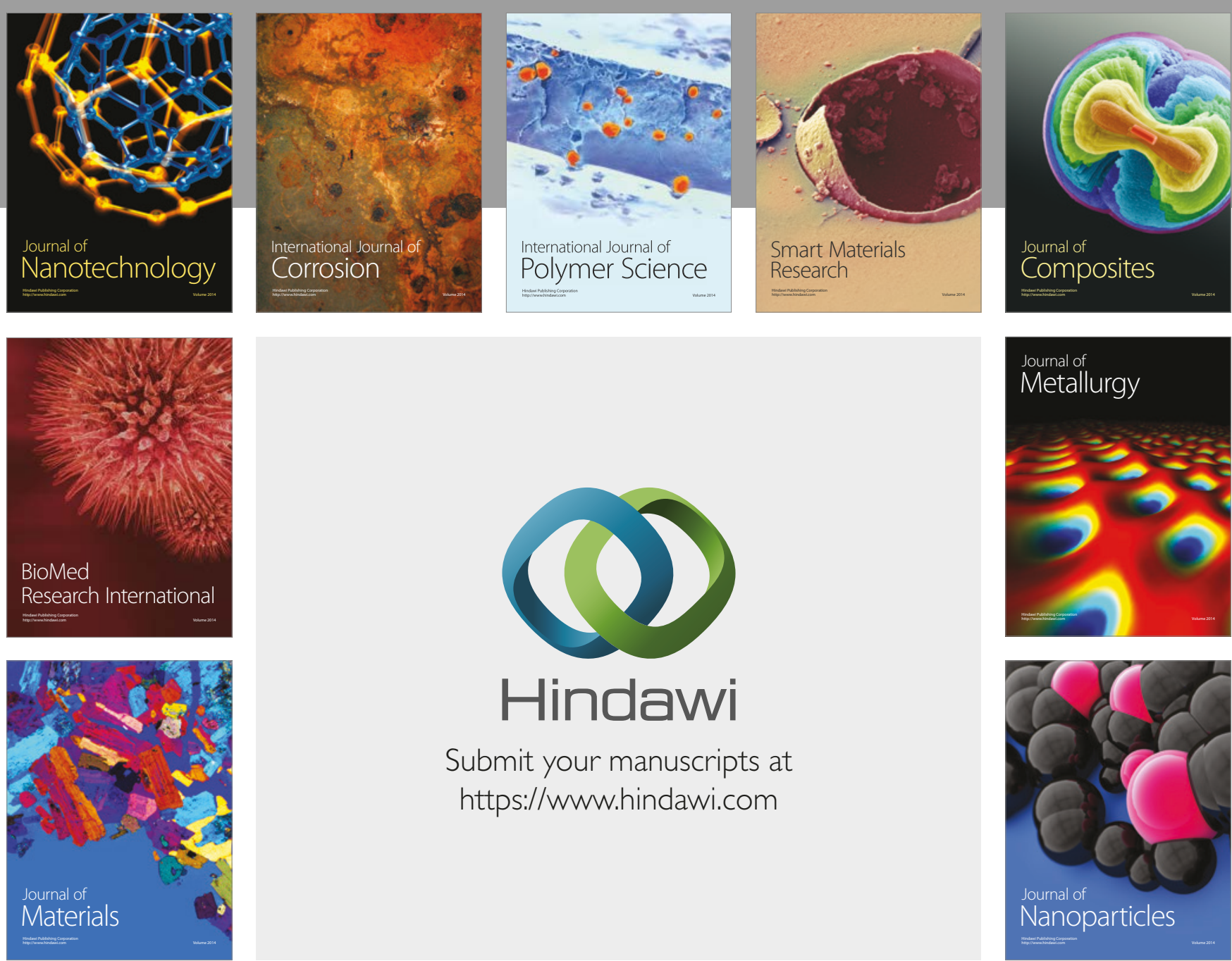

\section{Hindawi}

Submit your manuscripts at

https://www.hindawi.com
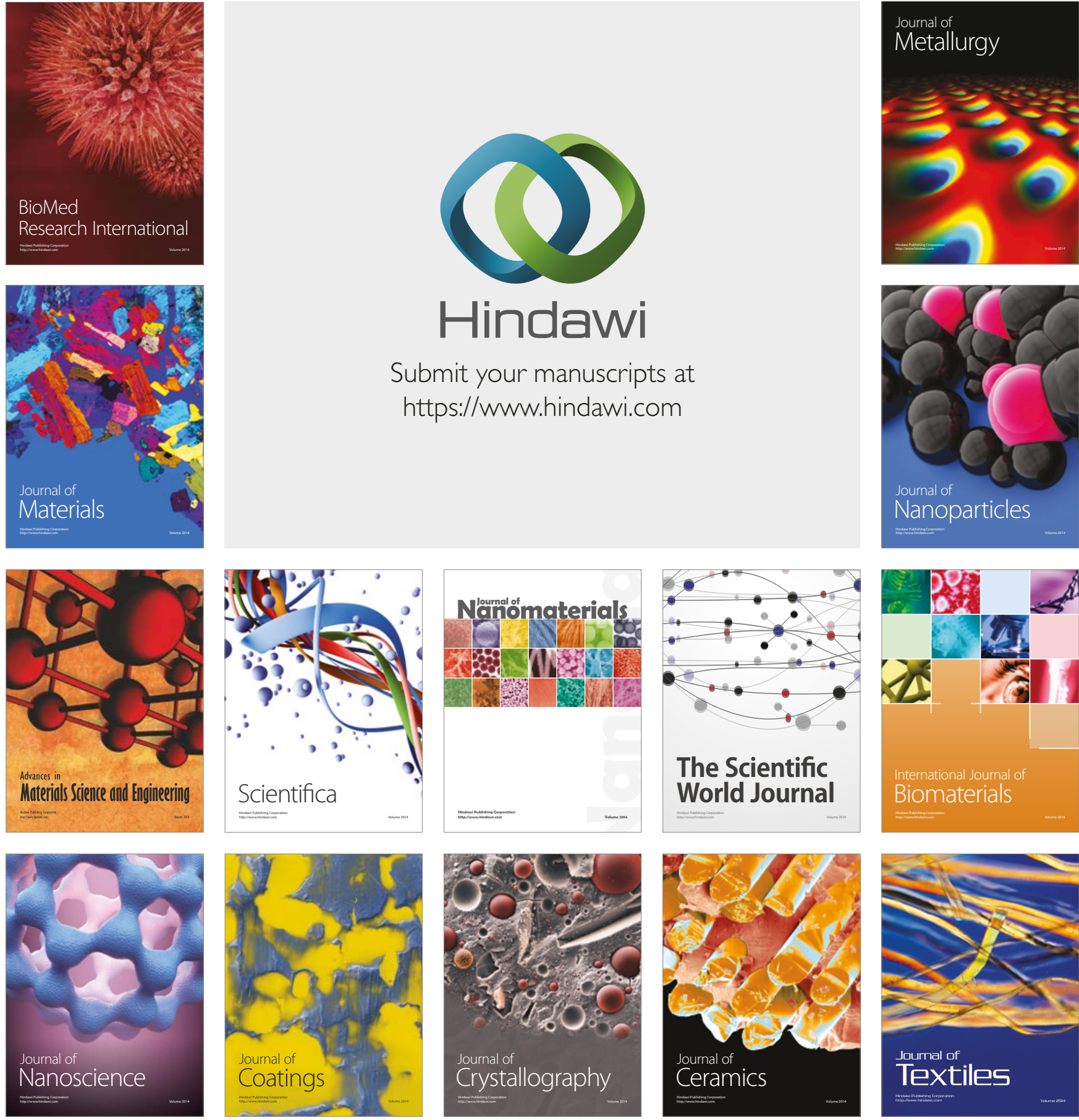

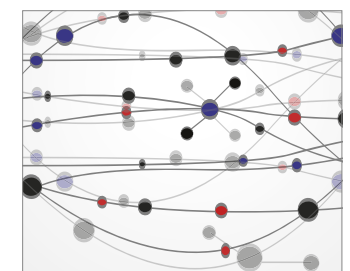

The Scientific World Journal
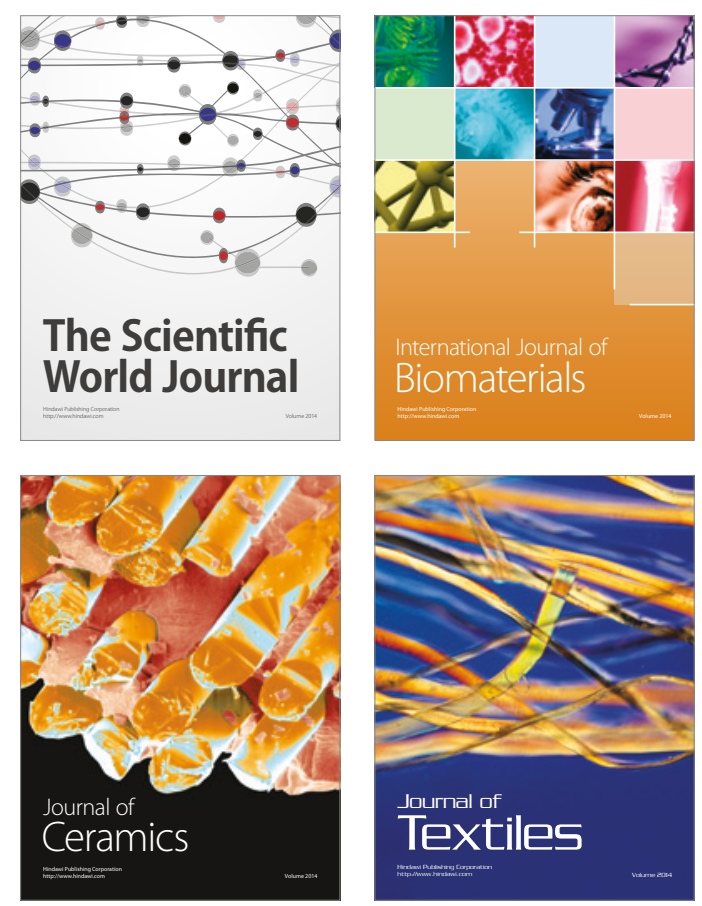